\title{
Conflicto en las zonas de conservación de la microcuenca de Córrego Água Limpia (São Paulo - Brasil)
}

\author{
Rodrigues, V.A., ${ }^{(1, *)}$ Madruga, P.R. de A, ${ }^{(2)}$ Garcia Morote, F.A., ${ }^{(3)}$ Lucas-Borja, M.E. ${ }^{(3)}$ \\ ${ }^{1}$ Universidade Estadual Paulista - FCA - UNESP - Botucatu - São Paulo - Brasil. \\ ${ }^{2}$ Universidade do Pampa - UNIPANPA - Alegrete - Rio Grande do Sul - Brasil. \\ ${ }^{3}$ Universidad de Castilla-La Mancha - UCLM - Albacete - España. \\ e-mail: valdemirrodrigues@fca.unesp.br
}

\section{Resumen}

El estudio de una microcuenca además de abarcar un contexto hidrológico, implica aspectos ecológicos, económicos y sociales. En este último se hará énfasis para identificar, cuantificar y determinar las áreas de conflicto en relación a los usos de suelo en la microcuenca de Córrego Água Limpa (São Paulo, Brasil); para ello se elaboró un mapa de usos del suelo, utilizando imágenes del sensor LISS3, de región del espectro electromagnético (banda 3), infrarrojo próximo (banda 4) e infrarrojo medio (banda 5). Los criterios de interpretación de imágenes fueron: patrones de asociación de objetos, textura, tonalidad, color y forma. Los usos de suelo fueron: cultivos agrícolas, plantaciones de caucho, pastos, vegetación autóctona, cursos de agua, zonas urbanas. Con el mapa de usos del suelo se identificaron las zonas de conservación de los ecosistemas fluviales. El cruce de la información gráfica de las áreas de conservación con el mapa de usos generó el mapa de conflictos de usos del suelo. La microcuenca tiene un área de 6398.25 ha y con el área de preservación permanente (APP) de 419.91 ha (6.56 \%). La superficie de conflicto de usos del suelo dentro las zonas de conservación es de 273.78 ha (65.20 \%). En las áreas de conflicto identificadas existe la necesidad de la sustitución de los cultivos y usos actuales (caña de azúcar y pastos) por vegetación autóctona, con la finalidad de conseguir una mayor sostenibilidad de los ecosistemas fluviales, para la conservación de los servicios ambientales y del agua generada en la microcuenca.

Palabras clave: Área de conservación permanente, microcuenca, usos del suelo, imagen digital. 


\section{Introducción}

El agua es un recurso natural renovable que se puede reciclar constantemente en el ciclo hidrológico, sistema: agua / suelo / planta / atmósfera, pero su disponibilidad es variable en el tiempo y el espacio. Las medidas de protección en la conservación de manantiales, bosques de ribera y la gestión del suelo en una cuenca son claves para mantener la producción de agua.

La Ley n ${ }^{\circ} 9433$ de 8 de enero de 1997, sobre la Política Nacional de Recursos Hídricos, establece las cuencas hidrográficas como unidades físico-territoriales para la planificación de recursos hídricos (Política Nacional de Recursos Hídricos Brasil, 1997). El bosque de ribera figura en el artículo $2^{\circ}$ de la Ley $n^{\circ} 4771 / 65$, abarcando como áreas de preservación permanente los bosques y otras formas de vegetación existentes en torno a los ríos, lagos, manantiales, lagunas y embalses, especificando, en la mayoría de los casos, el tamaño mínimo de la franja marginal que debe ser preservada. Esta franja es variable, dependiendo de la anchura de los cursos de agua. En el caso de los manantiales, el radio mínimo de la vegetación, debe ser $50 \mathrm{~m}$ (Brasil, 1965). En este último caso, se debe actuar con las medidas pertinentes en las áreas y canales sujetos al proyecto de restauración con un doble propósito: 1) reducir la vulnerabilidad de la cuenca para los efectos que provocan uma dinámica geo-torrencial; 2) contribuir a um uso sostenible. El uso adecuado de las diversas áreas de cobertura del suelo de la cuenca juega un papel clave en la consecución de ambos objetivos. En este contexto, el bosque contribuye de una manera especial, ya que es un elemento eficaz para regular el ciclo del agua y proteger el suelo de la erosión hídrica (Mintegui y López, 1990).

La importancia de una microcuenca no se limita a un contexto hidrológico, sino a una unidad compleja que implica aspectos ecológicos, económicos y sociales. De este modo, debido a que son las unidades de menor dimensión y que engloban todos los factores que influyen en el ciclo hidrológico, las microcuencas son adecuadas para la realización de estudios de producción hídrica, conservación y gestión del uso del suelo (Rodrigues et al., 2011) . Los bosques de ribera son fundamentales para preservar el ecosistema ripario y, comprenden el área variable de afluencia de agua (AVA), variando desde sitios mésicos, sin influencias de inundaciones, hasta áreas de inundación, donde las plantas se sumergen parcialmente o totalmente durante el período de inundación de los reservorios (Davide et al., 1996).

El uso de la teledetección y el geogrocesamiento para la delimitación de áreas de preservación permanente es fundamental para la correcta identificación de las APPs, concesión de licencias y cumplimiento de la legislación ambiental (Caldas, 2007). El diagnóstico hídrico del río Uberaba - MG (Minas Gerais), (Abdala, 2012) se utilizó como inicio para la gestión de las zonas de conflicto ambiental en dos épocas del año y se encontraron diferencias en la calidad del agua entre las estaciones seca y lluviosa.

Los Objetivos de este trabajo han sido, por un lado, identificar y cuantificar las áreas de conservación permanente $y$, por otro, determinar las áreas de conflicto en relación a los usos del suelo en la microcuenca del córrego Água Limpa (São Paulo, Brasil). 


\section{Material y métodos}

\subsection{Localización}

El estudio se llevó a cabo en la microcuenca del córrego Água Limpa que posee una superficie de 6.417 hectáreas, circunscrita entre las coordenadas geográficas: $\left(20^{\circ} 45^{\prime} 15^{\prime \prime}\right.$ a $20^{\circ} 51^{\prime} 48^{\prime \prime} \mathrm{S}$ y $49^{\circ} 37^{\prime} 48^{\prime \prime}$ a $\left.49^{\circ} 45^{\prime} 21^{\prime \prime} \mathrm{W}\right)$, localizada en el Planalto Ocidental Paulista, entre los municipios de Neves Paulista y Monte Aprazível, región oeste del Estado de São Paulo (Rodrigues y Carvalho, 2009), como se observa en la Figura 1 .

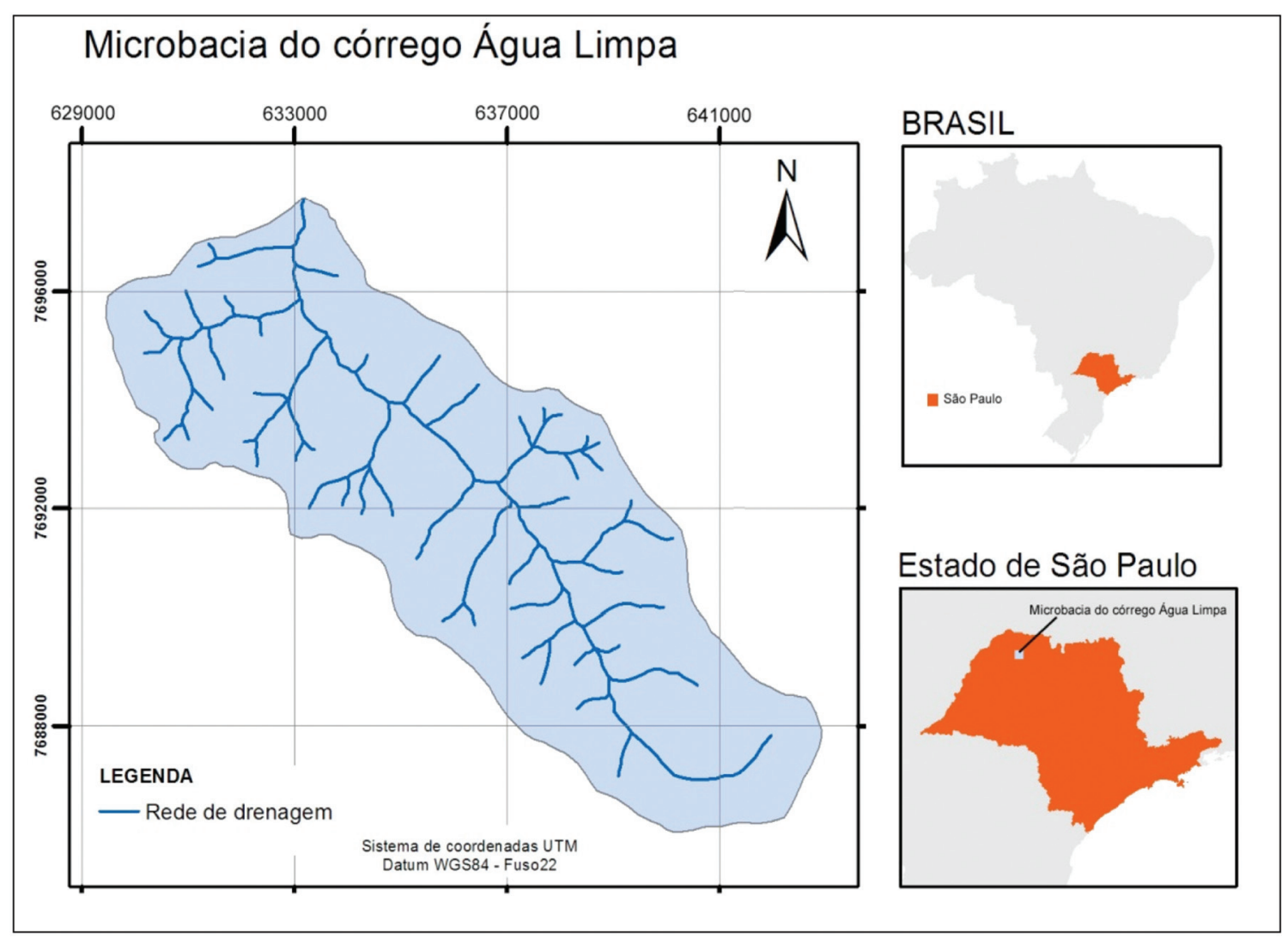

Figura 1. Microcuenca Hidrográfica del Córrego Água Limpa (São Paulo, Brasil).

La microcuenca del Córrego Água Limpa representada en la Figura 1, desagua en el río São José dos Dourados que tiene su desembocadura en el Río Paraná en la municipio de Pereira Barreto - SP. En el proceso de ocupación de esa cuenca se destacó la actividad de industria cafetera y la expansión del ferrocarril Araraquarense al río Paraná. Las plantaciones de café ejercieron gran influencia en el crecimiento demográfico y económico en el territorio del estado paulista, desencadenando cambios ambientales, y por lo tanto, importantes impactos sobre los recursos hídricos (IPT, 2011b).

Actualmente las áreas de ocupación de la microcuenca se han utilizado intensivamente como plantaciones de: caña de azúcar, caucho, pastizales, vegetación nati- 
va, otros usos, áreas de preservación permanente (APP), el agua en los cauces de ríos y presas, y construcciones en las áreas urbanas de los municipios de Neves Paulista y Monte Aprazível, ambos en el estado de São Paulo.

\subsection{Caracterización física de la microcuenca}

La caracterización de la red de drenaje y la cuantificación de los manantiales de la microcuenca se llevaron a cabo con el Mapa topográfico del (INSTITUTO BRASILEIRO DE GEOGRAFIA E ESTATÍSTICA - IBGE, 1972), a escala 1: 50.000, y la equidistancia entre las curvas de nivel de 20 metros. La microcuenca es de $4^{\circ}$ orden de ramificación de los cauces según (Strahler, 1957). La pendiente media es del $5.4 \%$, el factor de forma de 0.31 y la densidad de drenaje de $1.1 \mathrm{~km} / \mathrm{km}^{2}$, todos estos parámetros considerados bajos de acuerdo con Rodrigues y Carvalho, (2009).

\subsection{Caracterización climática}

El clima de acuerdo a la clasificación climática de Köppen es de tipo Cwa, cálido húmedo con invierno seco, donde la temperatura media en el mes más cálido es superior a $22^{\circ} \mathrm{C}$ y el mes más frío es inferior a $18{ }^{\circ} \mathrm{C}$. La precipitación media anual es de $1.420 \mathrm{~mm}$ (IPT, 2011).

\subsection{Cartografía de la microcuenca}

El mapa temático de uso de la tierra fue elaborado a través de la clasificación digital supervisionada, utilizando imágenes del sensor LISS3, bandas 3, 4 y 5, órbita punto 328-092, de 08/17/2013, región del espectro electromagnético correspondiente al rojo, infrarrojo cercano e infrarrojo medio, respectivamente. Se clasificaron los siguientes usos del suelo: caña de azúcar, caucho, pastizales, vegetación nativa, agua, zona urbana, otros usos.

Las imágenes están disponibles a través de la dirección wep http://www.dgi.inpe. br. Con el fin de obtener una mejor visualización y elaborar la imagen del mapa, se creó una composición de color RBG (543).

El método de clasificación utilizado fue la clasificación supervisionada, teniendo en cuenta el conocimiento previo de las áreas de estudio y adoptando criterios de interpretación de imágenes, tales como: patrones de asociación de objetos, textura, tonalidad, color y forma, procediendo de este modo una selección de muestras fiables. Posteriormente fue creada una firma espectral para cada clase. Para la clasificación automática se utilizó el método de Máxima Verosimilitud (MAXVER) que se basa en el cálculo de la distancia estadística entre cada píxel y la probabilidad de que cada píxel pertenezca a una determinada clase, con una opción de igual probabilidad de ocurrencia para cada firma y una relación de exclusión de los píxeles de $0 \%$, clasificando de esta manera, todos los píxeles de la imagen.

En la elaboración del mapa de conflictos de uso de la tierra, inicialmente fue digitalizada la red de drenaje de la microcuenca y sus respectivos manantiales. Utilizan- 
do la aplicación computacional de geoprocesado, fue elaborado un buffer de 30 metros a lo largo de toda la red de drenaje, así como un buffer de 50 metros en todos los manantiales, según determina la legislación vigente. Después de completar la elaboración del mapa de las áreas de preservación permanente, realizado el cruce con el

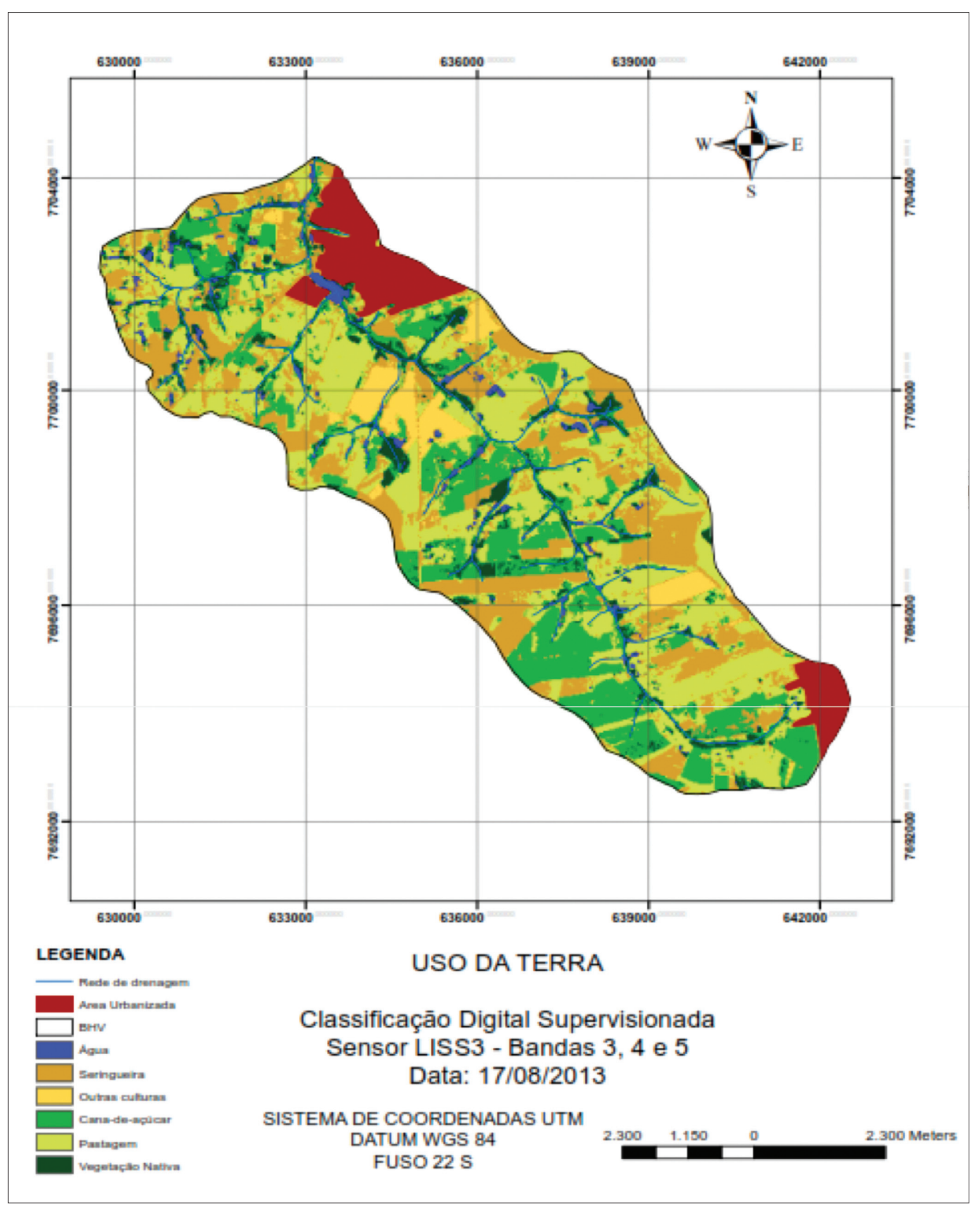

Figura 2. Uso de la tierra en la microcuenca do córrego Água Limpa (São Paulo, Brasil). 
mapa de uso de la tierra, generando el mapa de conflictos de uso. Estos conflictos fueron determinados cuando las áreas de preservación permanente, que deben contener la vegetación nativa, presentan agricultura.

\section{Resultados y discusión}

\subsection{Uso de la tierra en la microcuenca}

El mapa de uso de la tierra con la diversidad de los cultivos agrícolas, bosques, pastizales y áreas de preservación permanente (APP) en torno a los manantiales y red de drenaje, entre otros usos se muestran en la Figura 2.

En la Figura 2 se observa la redistribución de las zonas de ocupación y usos del suelo que en la actualidad son de plantaciones: caña de azúcar, caucho, pastizales, otros cultivos y la vegetación nativa en las áreas de preservación permanente (APP), así como la ocupación con agua en la red de drenaje y represas, y las zonas urbanas, aguas arriba y aguas abajo de la microcuenca. La frecuencia y los porcentajes de estas áreas de ocupación, así como las zonas de conflicto de uso de la tierra en las zonas de (APP) se representan en la Tab. 1.

Tabla 1. Uso y ocupación del suelo de la microcuenca Córrego Água Limpa (São Paulo, Brasil)*

\begin{tabular}{|c|c|c|c|c|}
\hline \multirow[t]{2}{*}{$\begin{array}{c}\text { USO DE } \\
\text { LA TIERRA }\end{array}$} & \multirow[t]{2}{*}{ ÁREA (ha) } & \multirow[t]{2}{*}{ FREC. $(\%)$} & \multicolumn{2}{|c|}{$\begin{array}{l}\text { CONFLICTOS DE USO } \\
\text { DE LA TIERRA EN APP }\end{array}$} \\
\hline & & & ÁREA (ha) & FREC. $(\%)$ \\
\hline Caña de azúcar & 1394.80 & 21.80 & 108.33 & 39.57 \\
\hline Caucho & 1586.34 & 24.79 & 45.84 & 16.75 \\
\hline Pastizales & 2198.46 & 34.36 & 116.31 & 42.48 \\
\hline Otros Cultivos & 241.93 & 3.78 & 3.30 & 1.20 \\
\hline Vegetación nativa & 377.03 & 5.89 & - & - \\
\hline Água & 163.83 & 2.56 & _ & _ \\
\hline Área urbana & 435.86 & 6.82 & - & - \\
\hline Total & 6398.25 & 100 & 273.78 & 100 \\
\hline APP & 419.91 & 6.56 & 273.78 & 65.20 \\
\hline
\end{tabular}

*Hectáreas (ha), porcentaje (\%), frecuencia (Frec.).

En cuanto al uso de la tierra representado en la Tab. 1, se observa que la superficie total de la microcuenca es de 6398.25 ha y una redistribución de los tres cultivos principales con una amplia cobertura de $80.94 \%$ de la superficie total, con: $21.80-$ 24.79 - 34.36, respectivamente de caña de azúcar, caucho y pastos.

La microcuenca de córrego Água Limpa tiene una superficie de preservación permanente de 419.91 ha, que corresponde al $6.56 \%$ de la superficie total de la microcuenca, la cual tiene uma importância fundamental en la preservación de los re- 
cursos hídricos. Pero el problema radica en la zona de conflicto de uso del suelo dentro del área de preservación permanente (APP) en la microcuenca.

Las áreas de reserva de bosques nativos redistribuidas en la microcuenca son de 377.03 ha, es decir, $5.89 \%$ de la superficie total. Esto demuestra que el uso actual de la microcuenca no cumple con la legislación de reserva legal, considerado de $20 \%$ para el estado de São Paulo. Sin embargo, cuando se cuantifica el cultivo de caucho que alcanza una superficie de $1586.34 \mathrm{ha}$, con $24.79 \%$ conjuntamente con una masa nativa de cobertura para 1963.37 ha, que corresponde al 30.68\% de la superficie total.

El área de conflicto de usos es de 273.78 ha, lo que corresponde al $65.20 \%$ de las 419.91 ha requeridas de APP. Debido a la necesidad de sustitución de cultivos, principalmente caña de azúcar y pastos para la restauración de la vegetación de ribera a lo largo de los cauces fluviales, con la finalida de un ecosistema de ribera más sostenible, fundamental en la conservación de los servicios ambientales de la microcuenca. De acuerdo con (Martí, 2011), la riqueza en biodiversidad y los numerosos beneficios ambientales de un bosque de galería en buen estado de conservación, hacen que cualquier intervención para proteger o rehabilitar estos ecosistemas riparios sea un excelente ejercicio y ayuda a la naturaleza y su ciclos de vida.

Las áreas urbanas no tienen APP, así como todas las zonas cubiertas por agua y vegetación nativa, por lo que no presentan conflictos de uso del suelo, por el contrario a partir de ciertos puntos existen vertidos que comprometen la calidad del agua para los municipios de su ámbito de aplicación. Las zonas riparias y los bosques de ribera con graves problemas de degradación requieren medidas de gestión que favorecen la conservación de los ecosistemas forestales de ribera en buen estado, así como la regeneración de los que se encuentran degradados (Cañadas et al., 2004). Además, la calidad del agua y el régimen de flujo de agua son fundamentales para el mantenimiento de las condiciones ambientales para mantener el estado de conservación favorable de los bosques de ribera y sus especies en este hábitat (Howell, 2011).

Cuando las zonas de conflicto son excesivas, los manantiales pierden la capacidad de producción de agua, por lo tanto, el ambiente de contribución natural de infiltración en su entorno, la zona de recarga del nivel freático, fue alterada por acciones antrópicas que comprometen su reabastecimiento y la producción de agua (Rodrigues, 1996). La metodología de recuperación y conservación de manantiales, paso a paso, con la recomendación de especies, implementación, gestión y orientación a los agricultores pueden ser claramente observados según (Davide et al., 2010).

\section{Conclusiones}

La zona de conflicto de uso de la tierra dentro de las áreas de preservación permanente (APP) corresponde a $65.20 \%$. Por tanto, existe la necesidad de sustituir el cultivo de caña de azúcar y pastos para la restauración de la vegetación nativa a lo largo de los manantiales y la red de drenaje de agua, con el fin de conseguir mayor sostenibilidad de los ecosistemas ribereños, vital para la conservación de los servicios ambientales de la microcuenca. 


\section{Bibliografía}

Abdala, V. L., 2012. Diagnóstico hídrico do rio Uberaba-MG como subsídio para a gestão das áreas de conflito ambiental. $61 \mathrm{f}$. Tese (Doutorado em Agronomia/Ciência do Solo) - Faculdade de Ciências Agrárias e Veterinárias, UNESP.

CONAMA n³57, 2005. Diário Oficial da União, Brasília, DF. Disponível: http://www. mma.gov.br/port/conama/res/res05/res35705.pdf. Acesso: 8 set. 2014.

Caldas, P.F., 2007. Geoprocessamento aplicado na delimitação de Áreas de Preservação Permanente em Jaraguádo Sul - SC. Seropédica: UFRRJ, 2007.

Cañadas, E. et al., 2004. Metodologi_a para el estudio de la vegetacio_n de ribera en la planificacio_n de las actuaciones en sistemas fluviales. In: Congreso ibe_rico de gestio_n y planificacio_n del agua. Tortosa, España.

Clarke, R. y King, J. O, 2005. Atlas da água. São Paulo, Brasil.

Howell, D., 2011. La Directiva Marco del Agua, las riberas y los objetivos de conservación. In:Marti, R. Manuales de desarrollo sostenible: recuperación deriberas. Madrid, España.

IBGE, 1972. Carta do Brasil: município de Mirassol. Escala 1:50.000. São Paulo, Brasil.

São Paulo (Estado), 2008. Instituto de Pesquisas Tecnológicas. Plano de bacia da unidade de gerenciamento de recursos hídricos do rio São José dos Dourados - UGRHI 18. (Relatório Técnico no 87.018-205). Disponível em: http:/www.sigrh.sp.gov.br/sigrh/ ARQS/RELATORIO/CRH/CBH-SJD/1239/sjd_plano\% 20 de\%20bacia.pdf. Acesso em: 16 set. 2014.

IPT. Instituto de Pesquisas Tecnológicas. Diagnóstico da situação atual dos recursos hídricos e estabelecimento de diretrizes técnicas para a elaboração do Plano da Bacia São José dos Dourados. São Paulo, 2007. (Relatório Técnico n 40.675). Disponível em: $<$ http://www.sigrh.sp.gov.br/sigrh/ ARQS/RELATORIO/ CRH/ CBH-SJD/1127/ volume\%201.pdf. Acesso em: 16 set. 2014.

IPT, 1981. Mapa geológico do Estado de São Paulo. São Paulo: IPT, 1981a.v. 1, 126 p. Escala 1:500.000. São Paulo, Brasil.

IPT, 1981. Instituto de Pesquisas Tecnológicas. Mapa geomorfológico do Estado de São Paulo. São Paulo: IPT, 1981b. v. 1, 94 p. Escala 1:1000.000. São Paulo, Brasil.

Mapa florestal dos municípios do Estado de São Paulo, 2009. Instituto Florestal. São Paulo. Escala 1:140.000. ttp://www.iflorestal.sp.gov.br/sifesp/estadosaopaulo/ nevespaulista. pdf. Acesso: 08 set. 2014.

Marti, R., 2011. Manuales de desarrollo sostenible: recuperación de riberas. Madrid, España.

Mintegui, J. M. A. y López, F. U. 1990. La ordenación agrohidrológica en La planificación. Departamiento de Agricultura y Pesca. Gobierno pais Vasco.

RODRIGUES, V. A. 2014. Avaliação dos processos hidrológicos em microbacias hidrográficas. $125 \mathrm{f}$. Tese (Livre docência) - Universidade Estadual Paulista. Faculdade de Ciências Agronômicas. Botucatu, São Paulo, Brasil..

Rodrigues, V. A. et al., 2012. Avaliação do fluxo de água dos canais nas ruas de Freiburg Alemanha. Revista Científica Eletrônica de Engenharia Florestal, Garça, v. 19, n. 1, p.13-22.

Rodrigues, V. A., 2011. Análise dos processos hidrológicos em modelo didático de microbacias. Revista Científica Eletrônica de Engenharia Florestal, Garça, v. 17, n. 1, p.1-15. 
Rodrigues, V.A. y Carvalho, W.A., 2009. Morfometria da microbacia do córrego Água Limpa. IF Sér. Reg., n. 39, São Paulo, Brasil. p.15-24.

Rodrigues, V.A., 2006. Recuperação de nascentes em microbacia da Cuesta de Botucatu. In: Rodrigues, V.A.; Bucci, L.A. Manejo de microbacias hidrográficas: experiências nacionais e internacionais. Botucatu: FEPAF, 2006. p. 5-28.

Strahler, A.N., 1957. Quantitative analysis of watershed geomorphology. Transactions of American Geophysical Union, New Haven, v. 38, p. 913-920.

Teixeira, C.G., 2011. Pagamento por serviços ambientais de proteção às nascentes como forma de sustentabilidade e preservação ambiental. Dissertação (Mestrado em Direito Socioambiental) CCJS - Pontifícia Universidade Católica do Paraná. Curitiba, 2011. $197 \mathrm{p}$.

Tundisi, J.G. y Matsumura-Tundisi, T., 2008. Liminologia. São Paulo: Oficina de textos, 2008. 632p. 
